\title{
Formulation and Evaluation of Film Forming Solution of Diphenhydramine Hydrochloride for Transdermal Delivery
}

\author{
Akhil Baby*, Hagalavadi Nanjappa Shivakumar, Prajila Alayadan \\ Department of Pharmaceutics, KLE College of Pharmacy, Bangalore, Karnataka, INDIA.
}

\begin{abstract}
Aim: The present work intends to formulate and evaluate film forming solution of diphenhydramine. Materials and Methods: Film forming solutions (FFS) for transdermal delivery of Diphenhydramine $\mathrm{HCl}$ were prepared using different polymers (hydroxypropyl cellulose, Eudragit L 100, polyvinylpyrollidone K30 and polyvinylpyrollidone K90), PEG 400 as plasticizer and ethyl alcohol as solvent. Results: The film forming solutions were found to display an acceptable drying time ranging from 2 to $5 \mathrm{~min}$. In-vitro release studies indicated percentage drug released by the end of $8 \mathrm{~h}$ from FFS of HPC-EF, Eudragit L 100 and PVP K 30 was found to be $41.31 \pm 2.1 \%, 14.81 \pm 1.2 \%$ and $25.7 \pm 1.9 \%$ respectively. FFS of HPC-EF that readily released drug were considered for further development by incorporating penetration enhancers like azone, isopropyl myristate and oleic acid. Steady state flux of drug across shed snake skin used as a barrier in vertical Franz diffusion cell was found to be $42.27 \pm 3.5 \mathrm{mg} / \mathrm{cm}^{2} / \mathrm{hr}, 51.18$ $\pm 4.9 \mathrm{mg} / \mathrm{cm}^{2} / \mathrm{hr}$ and $57.91 \pm 7.2 \mathrm{mg} / \mathrm{cm}^{2} / \mathrm{hr}$ for FFS containing isopropyl myristate, oleic acid and azone as permeation enhancers respectively. Conclusion: Considering the plasma clearance of the drug and transdermal steady state flux, it can be inferred that FFS containing azone as enhancer needs to be spread across an application area of $0.5 \mathrm{~cm}^{2}$ to elicit a therapeutic response.
\end{abstract}

Key words: Film forming solution, Diphenhydramine $\mathrm{HCl}$, Antihistamine, Transdermal delivery, Shed snake skin.

\section{INTRODUCTION}

Diphenhydramine $\mathrm{HCl}$ is a first-generation H1 receptor antihistamine that is used extensively for the treatment of seasonal allergies, insect bites, stings and rashes. However, it also has antiemetic, antitussive, hypnotic and anti-Parkinson properties. ${ }^{1,2}$ Due to its binding to muscarinic receptor along with $\mathrm{H} 1$ receptors, diphenhydramine hydrochloride is used as an adjuvant therapy in case of drug induced extrapyramidal symptoms associated with the use of antiParkinson drugs and anti-psychotics. ${ }^{3}$ It is also used as an analgesic adjuvant in refractory cancer pain in those patients who have failed to obtain adequate analgesia with opioids and conventional adjuvants. ${ }^{4}$ However, diphenhydramine
$\mathrm{HCl}$ with a short half-life (2-9 hr) displays a low oral bioavailability of $40-60 \%$ due to extensive first pass metabolism. As a result frequent administration of the drug $(25 \mathrm{mg}$ to $50 \mathrm{mg}, 3$ to 4 times a day) is necessary to maintain a required plasma level of the drug. ${ }^{1,2}$

Transdermal delivery of drug can evade the first pass effect, improve the bioavailability and at the same time, deliver the drug in a predetermined and controlled rate through the skin. However, conventional transdermal patches are likely to display poor adhesion and therefore, show poor permeation. They are prone to cause skin irritation, cause pain while peeling and display poor aesthetic appeal, which reduces the patient
Submission Date: 24-06-2020; Revision Date: 14-08-2020; Accepted Date: 08-10-2021.

DOI: 10.5530/ijper.56.1.6 Correspondence:

Mr. Akhil Baby (M.Pharm), Department of Pharmaceutics, KLE College of Pharmacy, Bangalore-560010, Karnataka, INDIA.

E-mail: akhilbaby2014@gmail. com

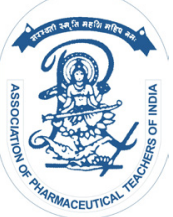

www.ijper.org 
compliance and desirability. Above all, the cost of the conventional transdermal patch would be high as the amount of drug that needs to be loaded into a patch is high to compensate the unavoidable drug wastage. These limitations of conventional transdermal patches can be overcome by film forming solution. ${ }^{5} \mathrm{~A}$ better substitute to conventional transdermal and topical dosage forms is the novel film forming solution. The major components of film forming solution are a polymer, plasticizer and a volatile solvent which aid in producing a drug loaded film in situ. Due to the loss of volatile solvent from the FFS, on application to skin, a residual drug loaded polymeric film along with other excipients is formed on the surface of the skin. As a result of this process, the drug concentration reaches saturation or possibly supersaturation level in the applied film. Supersaturation increases the thermodynamic activity of the drug which results in the enhanced drug flux through the skin, thereby improves the drug permeation through skin compared to other transdermal dosage forms. ${ }^{6}$ The film formed provides a controlled delivery of the drug into the systemic circulation by penetrating through different layers of the skin to elicit a therapeutic response. This continuous delivery of the drug prevents pulsed entry of drug into the systemic circulation thereby reduces the systemic toxicity. ${ }^{5,7}$ As this formulation is intended for a prolonged delivery of drug, to adapt to the movements of skin it should have high flexibility and also need to have strong skin adhesion for consistent drug delivery. Additionally, FFS may have superior cosmetic attributes to semi-solid formulations, as they are fast-drying, less greasy, well retained and are almost invisible once applied on the skin. Considering this, the present investigation aimed to prepare and evaluate FFS of diphenhydramine for transdermal delivery.

\section{MATERIALS AND METHOS}

\section{Materials}

Diphenhydramine $\mathrm{HCl}$, azone, isopropyl myristate and oleic acid were purchased from Yarrow Chem Pvt. Ltd., Mumbai. PVP K 30, PVP K90, HPC - EF and ethanol were purchased from Central Drug house Pvt. Ltd., New Delhi. Eudragit L 100 was a generous gift sample from Degussa Pvt. Ltd., Mumbai.

\section{Methods}

Preparation of film forming solution (FFS) of Diphenhydramine $\mathrm{HCl}^{5,7}$

The polymeric solutions were prepared by dissolving the polymer in the solvent and mixed using a magnetic stirrer until a clear solution was obtained. To the clear polymeric solution obtained, the plasticizer $(20 \% \mathrm{w} / \mathrm{w}$ of dry weight of polymer) was added and stirred. Into the resulting clear solution, the drug $(20 \% \mathrm{w} / \mathrm{v})$ was added and dissolved by continuously stirring until a clear solution of drug in the polymeric solution was obtained. A suitable permeation enhancer was selected and added based on the permeation of the drug. About 12 different formulations were prepared using four different polymers by varying the polymer concentration in three levels as per the Table 1.

\section{Physicochemical evaluation ${ }^{8}$}

Formulations were evaluated based on physicochemical properties of film formed upon casting the FFSs on a plane glass slide. Formulations were evaluated based on 5 parameters, appearance and viscosity of solution, drying time, outward stickiness and nature of formed film. Based on these physicochemical properties, suitable formulations were selected for further development.

\section{Appearance and microscopy ${ }^{8}$}

Both appearance and microscopy were evaluated based on visual examination. The drug loaded films, cast on plane slide were observed under electrical optical microscope (Labomed, Vision 2000) to detect possible crystallization of the drug, if any, on standing.

\section{Viscosity ${ }^{8}$}

Viscosities of the solutions were measured using Brookfield viscometer (Brookfield Ametek, BRK instruments) to determine the flow property of the solution. An ideal film forming solution should have low viscosity.

\section{Film formation ${ }^{8}$}

FFSs were cast on a plane slide to allow formation of film. Evaluation of film formed was rated as complete and uniform, incomplete or non-uniform. The film was also checked under electrical optical microscope (Labomed, Vision 2000) for possible precipitation, if any. The cosmetic facet of the films was evaluated based on transparency or opaque.

\section{Drying time ${ }^{8}$}

Formulations were cast onto a plane slide to determine drying time. After a set time span, another glass slide was mounted onto the film without pressure. Film is considered dry, if after removal there was no liquid visible on glass slide. Experiment was repeated with a rise in drying time if remains of liquid were visible on 
Table 1: Composition of film forming solution of diphenhydramine hydrochloride.

\begin{tabular}{|c|c|c|c|c|c|c|c|c|c|c|c|c|c|c|c|}
\hline Ingredients & F1 & F2 & F3 & F4 & F5 & F6 & F7 & F8 & F9 & F10 & F11 & F12 & F13 & F14 & F15 \\
\hline DPH HCl (w/v) & $20 \%$ & $20 \%$ & $20 \%$ & $20 \%$ & $20 \%$ & $20 \%$ & $20 \%$ & $20 \%$ & $20 \%$ & $20 \%$ & $20 \%$ & $20 \%$ & $20 \%$ & $20 \%$ & $20 \%$ \\
\hline Eudragit L $100(w / v)$ & $5 \%$ & $10 \%$ & $20 \%$ & - & - & - & - & - & - & - & - & - & - & - & - \\
\hline PVP K30 (w/v) & - & - & - & $5 \%$ & $10 \%$ & $20 \%$ & - & - & - & - & - & - & - & - & - \\
\hline PVP K90 (w/v) & - & - & - & - & - & - & $5 \%$ & $10 \%$ & $20 \%$ & - & - & - & - & - & - \\
\hline HPC (w/v) & - & - & - & - & - & - & - & - & - & $5 \%$ & $10 \%$ & $20 \%$ & $5 \%$ & $5 \%$ & $5 \%$ \\
\hline PEG $400(w / w)$ & $20 \%$ & $20 \%$ & $20 \%$ & $20 \%$ & $20 \%$ & $20 \%$ & $20 \%$ & $20 \%$ & $20 \%$ & $20 \%$ & $20 \%$ & $20 \%$ & $20 \%$ & $20 \%$ & $20 \%$ \\
\hline IPM (v/v) & - & - & - & - & - & - & - & - & - & - & - & - & $5 \%$ & - & - \\
\hline Oleic acid (v/v) & - & - & - & - & - & - & - & - & - & - & - & - & - & $5 \%$ & - \\
\hline Azone (v/v) & - & - & - & - & - & - & - & - & - & - & - & - & - & - & $5 \%$ \\
\hline Ethanol & qs & qs & qs & qs & qs & qs & qs & qs & qs & qs & qs & qs & qs & qs & qs \\
\hline
\end{tabular}

glass slide. A good FFS should have a minimum drying time to prevent long waiting for patients.

\section{Outward Stickiness ${ }^{8}$}

The outward film stickiness was measured by pressing a fixed weight of cotton wool onto dry film with low pressure. Stickiness was graded 'high' when dense fibre accumulation was seen on film, 'medium' when thin fiber layer was noted on film and 'low' when fibre adherence was seen occasionally or not seen, depending on the amount of cotton fibres retained by film. The details of all the physicochemical properties evaluated are captured in Table 3.

\section{In vitro release studies ${ }^{9}$}

The in vitro diffusion studies were carried out in vertical Franz diffusion cells using dialysis membrane $(12,000$ MWCO) as a barrier. The membrane was sandwiched between donor and receiver chamber and firmly secured between the two chambers using a stainless steel clamp. A tiny magnetic bead is used in the receiver chamber to stir the PBS ( $\mathrm{pH}$ 7.4) during the course of the experiment. About $0.5 \mathrm{~mL}$ of FFS solution was dispensed into the donor compartment and allowed to form a film. The receiver chamber was filled with buffer and the receiver was kept at $37.0 \pm 0.5^{\circ} \mathrm{C}$. About $1 \mathrm{~mL}$ of samples were withdrawn at predetermined time points from the receptor compartment and were replaced with fresh buffer equivalent to the volume withdrawn, before the samples were analyzed using UV spectrophotometer. To inspect the repeatability, studies were run in triplicate $(n=3)$.

\section{Ex vivo permeation studies ${ }^{9}$}

Ex-vivo permeation studies were carried out using shed snake skin as a barrier membrane for permeation of drug. A film was allowed to form on the barrier by adding $0.5 \mathrm{~mL}$ of FFS solution into donor chamber.
About $1 \mathrm{~mL}$ solution was drawn out from the receptor at $0,1,3,5,8,12,24 \mathrm{hr}$ and quantitatively analyzed for Diphenhydramine $\mathrm{HCl}$ using UV spectrophotometer. At every sampling time point, $1 \mathrm{~mL}$ PBS was replaced into the receptor port to maintain the volume. To examine reproducibility, trials were run thrice $(n=3)$.

\section{RESULTS AND DISCUSSION}

\section{Saturation solubility of drug in the polymeric solution}

Saturation solubility of drug in polymer solution was performed to check the crystallization point of drug in formulation, to determine stability of drug in formulation. The preformulation study was undertaken to fix the concentration of drug in the formulation. From the study, it was found that $40 \%$ of drug went into solution without crystallization, but solution formed by the addition of $40 \%$ and $30 \%$ of drug was highly viscous, displayed prolonged drying time and high outward stickiness, which was found to be undesirable to be formulate as FFS. Therefore, $20 \%$ of drug was selected as optimal concentration as FFS displayed good physicochemical properties. At the same time, this concentration of drug did not induce any skin irritation. Formulations containing 20\% drug were reported to be suitable for topical preparation that were irritation free. ${ }^{10}$

\section{Preformulation studies}

The UV spectra of diphenhydramine $\mathrm{HCl}$ displayed a $\lambda_{\text {max }}$ of $258 \mathrm{~nm}$ in PBS (pH 7.4). UV spectrophotometry was used as a tool to quantify the drug in all the studies undertaken. The infrared spectra of diphenhydramine $\mathrm{HCl}$ was found to display characteristic peak at $3031 \mathrm{~cm}^{-1}$ (due to aromatic $\mathrm{CH}$ stretching), $1381.75 \mathrm{~cm}^{-1}$ (due to $\mathrm{CH}_{3}$ bending), $1185.11 \mathrm{~cm}^{-1}$ (due to COC stretching) 

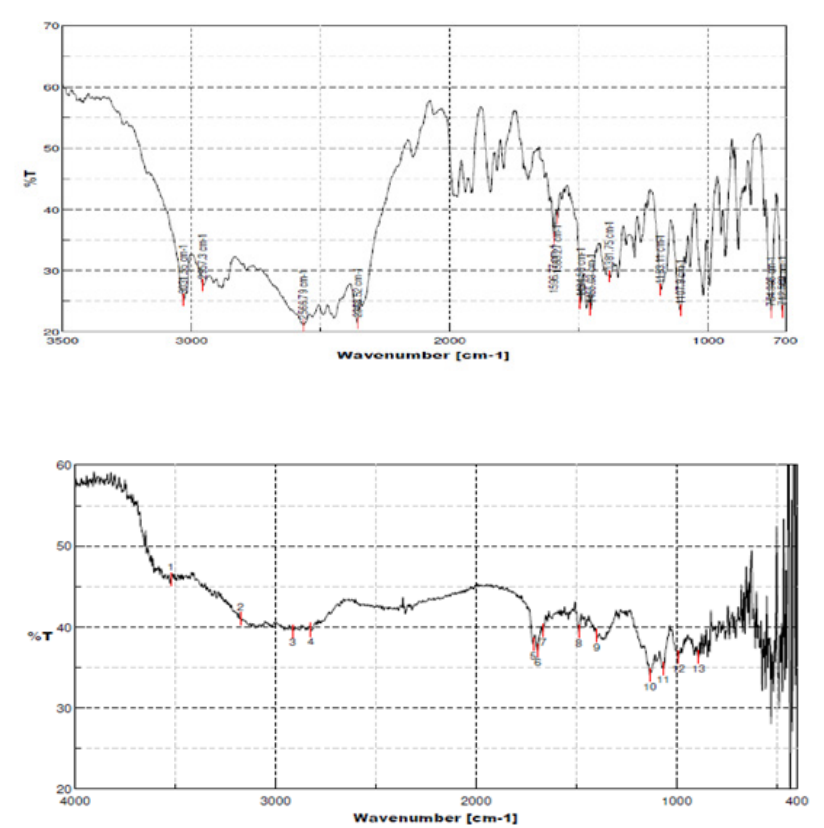

Figure 1: FTIR of diphenhydramine hydrochloride $[\mathrm{A}]$ and the optimized formulation [B].

\begin{tabular}{|c|c|c|c|}
\hline \multicolumn{4}{|c|}{ Table 2: Interpretation of FTIR studies of } \\
diphenhydramine hydrochloride. \\
$\begin{array}{c}\text { DPH HCI } \\
\text { Wavenumber } \\
\left(\mathbf{c m}^{-1}\right)\end{array}$ & Interpretation & $\begin{array}{c}\text { Formulation } \\
\text { Wavenumber } \\
\left(\mathbf{c m}^{-1}\right)\end{array}$ & Interpretation \\
\hline 3031 & $\begin{array}{c}\text { aromatic } \mathrm{CH} \\
\text { stretching }\end{array}$ & 3174 & $\mathrm{CH}_{\text {stretching }}$ \\
\hline 1381.75 & $\mathrm{CH}_{3}$ bending & 1399 & $\mathrm{CH}_{3}$ bending \\
\hline 1185.11 & $\begin{array}{c}\mathrm{C}-\mathrm{O}-\mathrm{C} \\
\text { stretching }\end{array}$ & 1133 & $\begin{array}{c}\mathrm{C}-\mathrm{O}-\mathrm{C} \\
\text { stretching }\end{array}$ \\
\hline 1455.03 & $\mathrm{CH}_{2}$ bending & 1488 & $\mathrm{CH}_{2}$ bending \\
\hline
\end{tabular}

and $1455.03 \mathrm{~cm}^{-1}$ (due to $\mathrm{CH}_{2}$ bending) displayed in Figure $1[\mathrm{~A}]$ and Table 2. The characteristic peaks of $\mathrm{DPH} \mathrm{HCl}$ were also seen in the spectra of formulations at $3174 \mathrm{~cm}^{-1}$ (due to $\mathrm{CH}$ stretching), $1399 \mathrm{~cm}^{-1}$ (due to $\mathrm{CH}_{3}$ bending), $1133 \mathrm{~cm}^{-1}$ (due to COC stretching) and $1488 \mathrm{~cm}^{-1}$ (due to $\mathrm{CH}_{2}$ bending) as displayed in Figure 1[B] and Table 2. These studies prove chemical integrity of drug in formulations and also rule out possible drug excipients interactions used in formulation of FFS. In conclusion, IR spectral observations demonstrated compatibility of DPH HCl and other excipients used. ${ }^{11}$

\section{Formulation aspects and evaluation}

As an initial step for the formulation it was important to identify a volatile solvent in which the drug has maximum solubility. From the literature survey it was found that the drug has maximum solubility in ethanol $(408 \mathrm{mg} / \mathrm{mL})$ when compared to other volatile solvents. ${ }^{11}$ Moreover, on formation of the drug loaded film, ethanol was found to evaporate quickly leaving behind a drug loaded film without any precipitation. PEG 400 was selected as plasticizer as it imparts good flexibility, smooth texture to the film. ${ }^{12}$ About 12 different formulations were prepared using four different polymers in varying concentration along with other excipients like plasticizer and a volatile solvent. Both hydrophilic and hydrophobic polymers were used to determine the effect of hydrophilicity of polymer and its concentration in the release of the drug from the formulation. Physicochemical evaluations of the formulations were performed to identify the best formulations that had desirable properties for both film forming solution and the formed film. The physicochemical properties of the films are depicted in Table 3. Viscosity of the solution and drying time of the film were the major parameters on which the formulations were categorized as pass or fail. An ideal formulation is required to have a quick drying time and low viscosity and low outward stickiness. ${ }^{5}$ It is desirable that, to avert clinging to the patients' clothes the films formed are non-tenacious. The films formed are expected to have low viscosity and short drying time to enable the film to quickly form. ${ }^{5}$ From the evaluation studies, it was found that, generally increasing the concentration of the polymer and plasticizer lead to an increase in viscosity of the solution and drying time of the formed film for hydrophilic polymers. On the other hand, hydrophobic polymer like Eudragit L 100 displayed no much difference in viscosity and drying time. So based on the physicochemical evaluations, the formulations which had good physicochemical properties were taken further for in-vitro release study followed by ex-vivo permeation study.

\section{In vitro release test}

The release of the drug from film forming solutions is depicted in Figure 2. From the release study, it was evident that the polymer type and its concentration significantly affected the release of the drug from the formulation. It was found that the hydrophilic polymer like PVP and HPC displayed better release property when compared to a hydrophobic polymer like Eudragit L 100. The release of drug from FFS composed of Eudragit L 100 as a film former was found to display poor release compared to polymers such as PVP K30, PVP K90 and HPC-EF. In addition, an increase in the concentration of polymer in FFS resulted in lower release values. Out of all four polymers used, HPC-EF at concentration of $5 \%$ displayed the maximum release 


\begin{tabular}{|c|c|c|c|c|c|c|}
\hline \multicolumn{2}{|c|}{ Table 3: Physicochemical evaluation of film forming solution of diphenhydramine hydrochloride. } \\
\hline Formulation & Appearance & Viscosity & Drying time & $\begin{array}{c}\text { Outward } \\
\text { stickiness }\end{array}$ & Film formation & Inference \\
\hline F1 & Clear & Low, Runny & $<5 \mathrm{~min}$ & Low & Uniform & Pass \\
\hline F2 & Clear & Low, Runny & $<5 \mathrm{~min}$ & Low & Uniform & Pass \\
\hline F3 & Clear & Low, Slightly viscous & $\leq 5 \mathrm{~min}$ & Low & Uniform & Pass \\
\hline F4 & Clear & Low, runny & $<5 \mathrm{~min}$ & Low & Uniform & Pass \\
\hline F5 & Clear & Low, Slightly viscous & $\leq 5 \mathrm{~min}$ & Medium & Uniform & Pass \\
\hline F6 & Clear & High & $>7 \mathrm{~min}$ & High & Uniform & Fail \\
\hline F7 & Clear & High & $>7 \mathrm{~min}$ & High & Uniform & Fail \\
\hline F8 & Clear & Highly viscous & $>7 \mathrm{~min}$ & High & Uniform & Fail \\
\hline F9 & Clear & Gel like consistency & $>7 \mathrm{~min}$ & High & Uniform & Fail \\
\hline F10 & Clear & Low, Runny & $<5 \mathrm{~min}$ & Low & Uniform & Pass \\
\hline F11 & Clear & Highly viscous & $5-7 \mathrm{~min}$ & High & Uniform & Fail \\
\hline F12 & Clear & Very highly viscous & $>7 \mathrm{~min}$ & High & Uniform & Fail \\
\hline F13 & Clear & Low, Runny & $<5 \mathrm{~min}$ & Low & Uniform & Pass \\
\hline F14 & Clear & Low, Runny & $<5 \mathrm{~min}$ & Low & Uniform & Pass \\
\hline F15 & Clear & Low, Runny & $<5 \mathrm{~min}$ & Low & Uniform & Pass \\
\hline
\end{tabular}

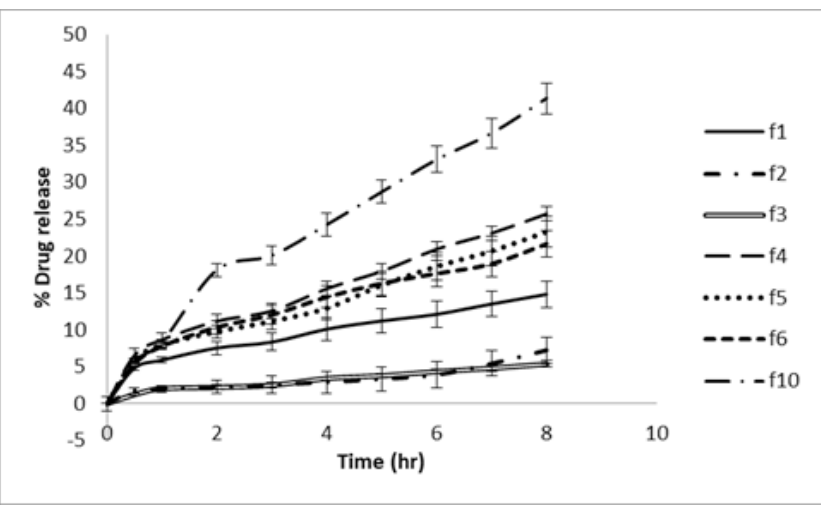

Figure 2: In vitro drug release profile of Film forming solutions.

of the drug. Nearly $40 \%$ of the drug got released from the formulation containing HPC, after a period of $8 \mathrm{hr}$ as indicated in Figure 2. Taking this into account, formulations composed of HPC were considered for further development considering the low viscosity, quick drying time and relatively better release of the drug. Moreover, the film made of HPC was found to be non-tacky and well retained for prolonged period of time on the skin without getting dissipated from the site of application.

\section{Ex vivo permeation studies}

After the release studies, the ex-vivo permeation of drug was performed using shed snake skin as a barrier in vertical Franz diffusion cells. Using shed snake skin as a barrier for permeation had advantages, there were no leaching of chemical substances from the skin into the diffusion medium, the skin required no pre-treatment prior to start of the experiment and required no specific storage condition as it was stable at room temperature. Shed snake skin is considered a barrier that simulates the human stratum corneum. ${ }^{13,14}$ Formulation of HPC (F10) without permeation enhancer was found to display a permeation of $685.41 \mu \mathrm{g} / \mathrm{cm}^{2}$ in $24 \mathrm{hr}$. However, to further improve the drug permeation though theskin, penetration enhancerswereincorporated to the FFS. Isopropyl myristate, oleic acid and azone were incorporated as penetration enhancers with the aim to increase the ex vivo permeation of DPH HCl. ${ }^{14}$ The concentration of the permeation enhancers were fixed as $5 \%$ so that the viscosity and the drying time of the FFS are unaffected. However, higher concentrations of permeation enhancer in the FFS increased the viscosity and the drying time which was not desirable. Oleic acid, IPM and azone have been used as penetration enhancer at a concentration of $5 \%$ to enhance the permeation of water soluble drug through the skin. ${ }^{15}$ The ex vivo permeation of drug from different formulations of HPC is depicted in Figure 3. The steady state flux values from formulations F13, F14 and F15 were found to be $42.27 \mu \mathrm{g} / \mathrm{cm}^{2} / \mathrm{hr}, 51.18 \mu \mathrm{g} / \mathrm{cm}^{2} / \mathrm{hr}$ and $57.91 \mu \mathrm{g} / \mathrm{cm}^{2} / \mathrm{hr}$ respectively. The transdermal steady state flux value for Diphenhydramine $\mathrm{HCl}$ from formulation $\mathrm{F} 15$ which contained azone as permeation enhancer was found to 


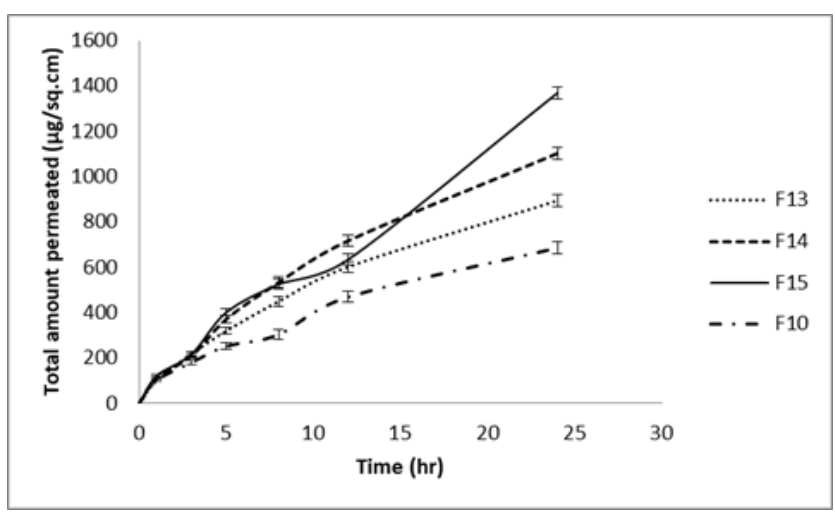

Figure 3: Ex vivo permeation of drug from film forming solution through shed snake skin.

be display the highest flux. Taking into account the PK parameters such as plasma clearance of $\mathrm{DPH} \mathrm{HCl}$, it is possible to calculate the area across which the FFS has to be spread to elicit a therapeutic response. Considering the PK parameter and the transdermal SS flux, it can be inferred that the FFS need to be spread across an area of $0.5 \mathrm{~cm}^{2}$ to elicit a therapeutic response.

\section{CONCLUSION}

FFS of DPH were successfully prepared using hydroxypropylcellulose, EudragitL100,PVPK30 andPVP K90 as polymers, PEG 400 as plasticizer and ethyl alcohol as solvent. The films formed were found to display low viscosity, low outward stickiness and short drying time. The films formed of HPC-EF were found to display relatively better release compared to other polymer investigated. Ex vivo permeation studies performed indicated that DPH HPC-EF films were able to successfully deliver therapeutic amount of drug across shed snake skin.

\section{ACKNOWLEDGEMENT}

The authors are thankful to the Principal of KLE College of Pharmacy, Bengaluru, for providing available facilities to perform this study.

\section{CONFLICTS OF INTEREST}

The authors declare no conflicts of interest.

\section{ABBREVIATIONS}

TDDS: Transdermal drug delivery system; FFS: Film forming solution; PVP: Polyvinyl pyrrolidone; HPC: Hydroxypropyl cellulose; PEG 400: Polyethylene glycol 400; IPM: Isopropyl myristate; DPH HCl: Diphenhydramine hydrochloride; IVRT: In vitro release test; PK: Pharmacokinetic.

\section{REFERENCES}

1. Drug bank.ca/drugs. Canada: Canadian Institutes of Health Research; updated 2020 Jul 16; [cited Jul 19 2019]]. Available from: https://www. drugbank.ca/drugs/DB01075.

2. Drug bank.ca/Salts. Canada: Canadian Institutes of Health Research; updated 2020 Jul 16; [cited Jul 19 2019]]. Available from: https://www. drugbank.ca/salts/DBSALT000056.

3. Weignand DA, Haygood C, Gaylor JR, Anglin JH. Racial variation in the cutaneous barrier in current concepts in cutaneous toxicity. Drill VA and Lazar P editors. New York: Academic press; 1980. p. 221-35.

4. Santiago-Palma J, Fischberg D, Kornick C, Khjainova N, Gonzales G. Diphenhydramine as an analgesic adjuvant in refractory cancer pain. J Pain Symptom Manage. 2001;22(2):699-703. doi: 10.1016/s0885-3924(01)00311-6, PMID 11495716

5. Saudagar RB. Formulation, development and evaluation of film-forming gel for prolonged dermal delivery of terbinafine hydrochloride. Int J Pharm Sci Res. 2014;5:537-40.

6. Paradkar M, Thakkar V, Soni T, Gandhi T, Gohel M. Formulation and evaluation of clotrimazole transdermal spray. Drug Dev Ind Pharm. 2015;41(10):1718-25. doi: 10.3109/03639045.2014.1002408, PMID 25579237.

7. Sivayathorn A, Verallo-Rowell V, Graupe K. $20 \%$ azelaic acid cream in the topical treatment of melasma: A double-blind comparison with $2 \%$ hydroquinone. Eur J Dermatol. 1995;5(8):680-4.

8. Florey K. Analytical profiles of drug substances. $1^{\text {st }}$ ed. Amsterdam: Elsevier; 2005.

9. Trovatti E, Freire CS, Pinto PC, Almeida IF, Costa P, Silvestre AJ, Neto CP, Rosado C. Bacterial cellulose membranes applied in topical and transdermal delivery of lidocaine hydrochloride and ibuprofen: in vitro diffusion studies. Int J Pharm. 2012;435(1):83-7. doi: 10.1016/j.jjpharm.2012.01.002, PMID 22266531.

10. Takahashi K, Tamagawa S, Katagi T, Rytting JH, Nishihata T, Mizuno N. Percutaneous permeation of basic compounds through shed snake skin as a model membrane. J Pharm Pharmacol. 1993;45(10):882-6. doi: 10.1111/ j.2042-7158.1993.tb05613.x, PMID 7904627.

11. Suh $\mathrm{H}$, Jun HW. Effectiveness and mode of action of isopropyl myristate as a permeation enhancer for naproxen through shed snake skin. J Pharm Pharmacol. 1996;48(8):812-6. doi: 10.1111/j.2042-7158.1996.tb03979.x, PMID 8887730.

12. Ammar HO, Ghorab M, Mahmoud AA, Makram TS, Ghoneim AM. Rapid pain relief using transdermal film forming polymeric solution of ketorolac. Pharm Dev Technol. 2013;18(5):1005-16. doi: 10.3109/10837450.2011.627867, PMID 22191998. 
PICTORIAL ABSTRACT

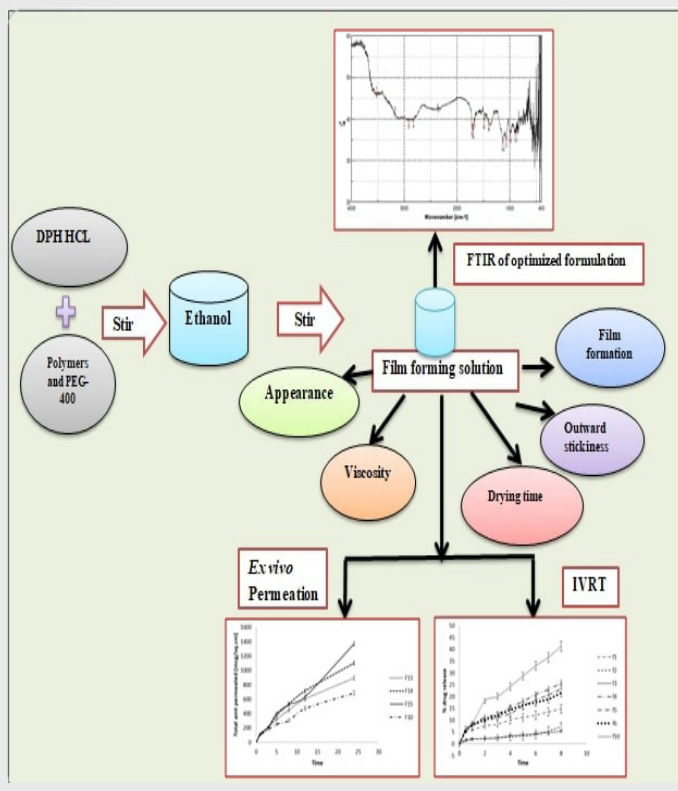

\section{SUMMARY}

Film forming solution of Diphenhydramine $\mathrm{HCl}$ was formulated using four different polymers like Eudragit L 100, HPC, PVP K30 and PVP K90. All the formulations were screened by physicochemical evaluations like viscosity, drying time, outward stickiness, appearance and film formation. The best formulations were chosen for in-vitro release and ex-vivo permeation studies. The formulation with 5\% HPC was found to show good release and permeation. It was also proved that Film forming solution of Diphenhydramine $\mathrm{HCl}$ was found to give good adhesion property and a controlled release of drug for over a period of $24 \mathrm{hr}$. Hence Diphenhydramine $\mathrm{HCl}$ as a transdermal candidate lay down proof for non-invasive drug delivery system.

\section{About Authors}

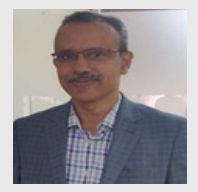

Dr. H.N. Shivakumar is Vice-Principal and Professor at KLE College of Pharmacy, Bengaluru, India. He has earned his doctoral degree from Rajiv Gandhi University of Heath Sciences, Karnataka and his postdoctoral research fellowship from The University of Mississippi, University, MS, USA. His research interest is focused on Chronotherapeutic Drug Delivery, Transdermal, Transungual Drug Delivery and Pharmaceutical development applying the principles of Quality by Design ( $\mathrm{QbD})$.

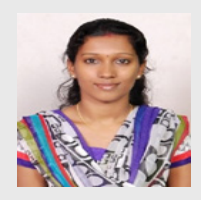

Mrs. Prajila A is a Ph.D Research Scholar at KLE College of Pharmacy, Bengaluru, India. She has 4 years of teaching experience. Her interest is focused on Transdermal Drug Delivery and Novel Drug Delivery.

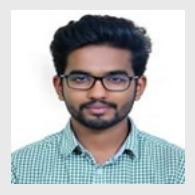

Mr. Akhil Baby did his Masters in Pharmaceutics from KLE College of Pharmacy, Bengaluru, India. His research interest is Transdermal Drug Delivery.

Cite this article: Baby A, Shivakumar HN, Prajila A. Formulation and Evaluation of Film Forming Solution of Diphenhydramine Hydrochloride for Transdermal Delivery. Indian J of Pharmaceutical Education and Research. 2022;56(1):43-9. 